\title{
Editorial
}

\section{Migrações e trabalho: precarização, discriminação e resistência}

Em muitos países, na atualidade, mudanças nas leis trabalhistas estão sendo implementadas com o objetivo, real ou fictício, de aumentar a competitividade em um contexto de crise econômica. Essas reformas, em geral, visam flexibilizar os contratos de trabalho e, ao mesmo tempo, alterar os processos de negociação coletiva. Na realidade, para além dos discursos oficiais, o que ocorre é uma redução dos direitos dos trabalhadores.

É nesse clima geral que milhões de migrantes e refugiados se inserem no mercado de trabalho dos países de trânsito e de destino. Apesar das legislações de muitos desses países reconhecerem, no papel, a igualdade de direitos laborais entre estrangeiros e nacionais, registra-se com frequência uma maior vulnerabilidade dos primeiros, vulnerabilidade que se acentua quando a condição migratória se intersecciona com questões de gênero, etnia ou religião. Assim sendo, guardadas as devidas exceções, os trabalhadores migrantes são os mais atingidos pelos efeitos da atual conjuntura, sobretudo em termos de desemprego, subemprego e sobrequalificação.

Mas não é só isso. Mesmo nos países menos afetados pela crise, os trabalhadores estrangeiros - assim como as segundas e terceiras gerações continuam envolvidos nos nichos laborais mais precários e subpagos. O trabalho, em muitos casos, deixou de ser um valioso instrumento de incorporação nas sociedades de chegada para se tornar um vetor de discriminação e exclusão social. Um verdadeiro muro para além dos muros das fronteiras.

É bom frisar que a exploração dos trabalhadores migrantes não visa apenas interesses imediatos e contextuais, mas esconde uma intencionalidade muito mais perversa: a precarização de todos os empregos. De fato, na ótica da racionalidade econômica hegemônica, o trabalhador perfeito é o gastarbeiter, o trabalhador hóspede, temporário, sem os entraves da família e dos sindicatos, com reduzida capacidade reivindicativa e urgente necessidade de dinheiro. A violação dos direitos laborais dos estrangeiros é, portanto, o ponto de partida para a vulnerabilização de toda a classe trabalhadora. 
Aprofundando a questão, é importante frisar também a vinculação entre políticas migratórias e trabalhistas. Encurralados entre a rigidez das primeiras e a flexibilidade das segundas, muitos migrantes vivenciam o drama da precarização do trabalho como risco real de deportação. Dito de outra forma, em muitos casos, é a intersecção entre políticas migratórias e trabalhistas que determina o clima de deportabilidade com todas as suas consequências.

Além disso, as políticas de cotas migratórias que são orientadas pelo assim chamado "princípio de disponibilidade" - a oferta de vistos para áreas do mercado de trabalho carentes de mão de obra - acabam por alimentar clivagens étnicas e raciais, afetando desta maneira aqueles indivíduos, sobretudo de segunda e terceira geração, que ousam aspirar empregos supostamente reservados a grupos étnicos nacionais.

Finalmente, nesse cenário sombrio, é mister atentar também para aquelas abordagens que enfatizam as capacidades de resistência e superação dos trabalhadores migrantes. Mesmo em contextos marcados por exploração e discriminação, há numerosos casos de pessoas em mobilidade que, recorrendo a sólidas redes étnicas, recuperando recursos culturais dos países de origem, aproveitando as oportunidades oferecidas por conjunturas econômicas ou nichos específicos do mercado de trabalho, conseguem trajetórias biográficas exitosas, para si, seus familiares e as sociedades de destino. Essas experiências atestam as potencialidades da agency dos migrantes e apontam para a necessidade de "contrarreformas trabalhistas" que garantam e ampliem os direitos de todos os trabalhadores de modo a valorizar, inclusive, suas habilidades e competências.

Estas são algumas das temáticas aprofundadas no dossiê da Revista REMHU n. 49. No primeiro artigo, Alejandro Canales desenvolve um estudo perspicaz acerca do acirramento da racialização da desigualdade social nos Estados Unidos, num contexto caracterizado pela polarização dos empregos e por intensas mudanças demográficas. De acordo com o autor, os dados estatísticos do mercado de trabalho norte-americano indicam de forma contundente a "racialización de la matriz social y laboral de los Estados Unidos", uma racialização que poderá afetar a coesão social de um país que registra uma composição demográfica cada vez mais diversificada.

A interseccionalidade entre as desigualdades de classe, gênero, etnia e cultura é aprofundada por Verónica Trpin e Cynthia Pizarro. Conforme as autoras, que focam a temática a partir das migrações circulares de trabalhadores rurais temporários na Argentina, as políticas de identidade tendem, com frequência, a essencializar traços culturais ou raciais com a consequente naturalização das desigualdades sociais. Desta forma, determinados grupos nacionais ou étnicos, por suas supostas características biológicas (genéticas ou fenotípicas), culturais, 
sociais ou psicológicas são relegados a determinados nichos do mercado de trabalho, geralmente os mais precários e vulneráveis.

Outro aspecto discriminante das políticas migratórias é focado por Laura Zanfrini, que se debruça sobre as políticas de gestão das labour migrations na Europa. Essas políticas tendem a promover o ingresso no território nacional apenas de trabalhadores "complementares", que se encaixam em setores do mercado de trabalho carentes de profissionais (o assim chamado "princípio de disponibilidade"). Com o passar do tempo, no entanto, os recém-chegados e seus familiares se tornam cada vez mais relutantes em aceitar "empregos de imigrantes", rejeitando a condição de eternos gastarbeiter. Uma mudança de rumo é sugerida pela autora, na ótica da criação de economias competitivas e inclusivas ou, melhor, economias competitivas porque inclusivas.

A precarização do trabalho, o impacto sobre os trabalhadores migrantes e o papel da imigração enquanto "taller de experimentación" de novas formas de precarização são temas abordados por Fabio Perocco. O autor aprofunda a situação da União Europeia e, de forma específica, da Itália, onde existe uma exacerbada segmentação racial no mercado laboral. A capilar difusão dos voucher - recentemente abolidos na Itália - e a crescente prática do trabalho voluntário gratuito são exemplos nítidos dessa "pedagogía de la precariedad" inerente ao hegemônico modelo econômico, uma pedagogia que visa atingir não apenas a mão de obra estrangeira, mas também a classe trabalhadora nacional.

Carolina Stefoni, Sandra Leiva e Macarena Bonhomme abordam o tema da precarização do trabalho no Chile, numa ótica interseccional. Focando o trabalho no setor da construção, as autoras ressaltam como a inclusão dos trabalhadores migrantes mais vulneráveis, em situação imigratória irregular, sem ligação com sindicatos, permitiu a criação e o aprimoramento de dispositivos que incrementam a negação de direitos trabalhistas. Sublinha-se, notadamente, os "anexos" do "contrato por obra" com todas as suas nefastas consequências.

E isso não diz respeito apenas à assim chamada mão de obra não qualificada. Telésforo Ramírez García e Fernando Lozano Ascencio examinam o novo cenário mundial acerca da migração de trabalhadores qualificados. Focando sua análise na América Latina e Caribe, os autores sustentam que esse tipo de migração aumentou muito no âmbito dos países da OCDE, envolvendo um grande número de latino-americanos e caribenhos, com destaque pelos trabalhadores de países andinos e pelas mulheres. Cabe salientar que o fenômeno apresenta aspectos negativos que afetam tanto a qualidade de vida dos migrantes quanto o desenvolvimento dos países de origem.

O impacto da crise econômico-financeira entre os trabalhadores migrantes - com foco específico nos brasileiros e brasileiras em Portugal - é o 
tema do artigo de Sónia Pereira e Alina Esteves. Várias temáticas são abordadas, como o forte desemprego entre os imigrantes, a crescente instabilidade laboral e o retorno. Ainda assim, as autoras inferem que brasileiros e brasileiras mantiveram "nichos de empregabilidade" em áreas do mercado de trabalho menos atingidas pela crise e, ao mesmo tempo, conservaram um alto grau de satisfação em relação à estadia em Portugal, em decorrência da qualidade de vida e dos serviços sociais disponíveis.

María José Martín Herrero, Maite Fouassier Zamalloa e Gorka Moreno Márquez também se debruçam sobre a relação entre crise econômica e mercado de trabalho, tendo como objeto epistêmico as mulheres migrantes no País Basco. Comparando dados estatísticos de 2010 e 2014, os autores realçam a importância das variáveis de gênero e da procedência. De fato, em termos gerais, os homens migrantes foram mais atingidos pela crise do que as mulheres. Por sua vez, as latino-americanas registraram maior empregabilidade do que as mulheres de origem africana. Em ambos os casos, no entanto, cresceu o número de pessoas empregadas no trabalho doméstico que, na ótica dos autores, se tornou um importante "nicho laboral refugio".

Esta busca de estratégias de resistência e superação diante de situações adversas é sublinhada por Roberto Benencia e Santiago Canevaro em seu estudo sobre a jornada migratória de trabalhadores bolivianos na Feira La Salada, em Buenos Aires. Mediante as paradigmáticas histórias de vida de dois entrevistados, os autores ressaltam como, atuando em espaços econômicos intersticiais, esses bolivianos conseguiram trajetórias trabalhistas exitosas, pois souberam aproveitar das oportunidades da conjuntura econômica e política, das sólidas redes étnicas e, inclusive, de práticas culturais aymara. O ser boliviano, desta forma, se tornou um importante recurso para gerenciar os desafios da nova realidade e alcançar o reconhecimento social.

A agência do migrante é o foco também do estudo que Bruno Miranda desenvolve sobre os trabalhadores bolivianos em oficinas de costura em São Paulo. Mesmo não menosprezando as formas de coação do trabalho não-livre, o texto focaliza sua reflexão nos mecanismos de construção de consentimento entre os donos das oficinas e os costureiros. Segundo o autor, existem mecanismos institucionais (derecho de piso, cama caliente e vales) e ideológicos à base de um acordo tácito entre as partes envolvidas, sendo o desrespeito desse acordo - mediante abusos ou enganos - que torna a relação conflitiva, o que, de qualquer forma, não suprime totalmente a agência dos trabalhadores.

Finaliza o Dossiê o artigo de Eduardo Rodríguez Rocha sobre iniciativas econômicas de migrantes chineses e senegaleses em Córdoba, na Argentina. Partindo de uma abordagem "transnacional" e "desde baixo", o autor descreve o funcionamento de cadeias mundiais de mercadorias e, no caso específico, 
dos processos que levam mercadorias desde a China até os bazares ou as ruas de Córdoba. O artigo analisa a relação de complementaridade e, ao mesmo tempo, de desigualdade entre chineses e senegaleses, inclusive no interior dos próprios grupos nacionais. Apesar de tudo, esse nicho econômico, nos limites porosos da (i)legalidade, constitui uma estratégia de emprego para quem vive às margens da economia hegemônica.

Na seção Artigos, Martina Pasqualetto apresenta um precioso estudo sobre a recente evolução legislativa italiana no que diz respeito ao assim chamado "voluntariado" dos solicitantes de refúgio promovido pelo governo italiano a fim de fortalecer a integração e a formação dos recém-chegados. Contrariando o discurso oficial, a pesquisadora argumenta que, na realidade, os recém-chegados são pressionados a assumir um "trabalho não-remunerado" que pouco contribui à integração, relativiza o direito de refúgio, alimenta um imaginário de inferiorização e, no fundo, visa implementar uma pedagogia da precarização com o propósito de introduzir os migrantes a um mercado de trabalho na ótica dos 3D-job (dirty, dangerous, demanding).

Finalmente, lana dos Santos Vasconcelos e Sandro Martins Almeida Santos abordam a relação entre a noção de família e as dinâmicas de mobilidade em dois contextos bastante diferentes: comunidades de vida "alternativas" em Goiás e garimpos na Venezuela. Segundo os autores, em ambos os casos existem nexos entre a construção social da noção de família e a mobilidade humana: no primeiro, a noção cosmopolita de família gera comunhão entre os moradores da comunidade e todos os recém-chegados, enquanto, no segundo, a noção de consanguinidade estabelece laços transnacionais, que permanecem sólidos apesar da distância geográfica. Em ambos os casos, no entanto, os laços familiares devem ser alimentados mediante atos de reciprocidade e troca de bens simbólicos ou materiais.

A seção Relatos e reflexões disponibiliza um texto de Laura Cristina Yufra sobre migrações, leis migratórias, lei trabalhistas e direitos sociais na Argentina, enquanto Marivane Chiesa, mscs relata sua experiência sócio-pastoral em países africanos junto a migrantes e refugiados. A resenha de Carmem Lussi do livro Sulle onde delle migrazioni encerra este número da Revista.

Desejamos a todos e todas uma boa leitura!

Roberto Marinucci (editor-chefe da REMHU) 